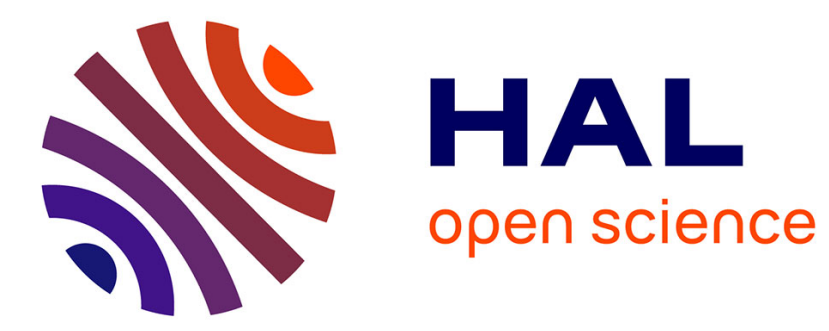

\title{
EVIDENCE FOR DETERMINISTIC CHAOS IN LONG-TERM HIGH-RESOLUTION KARSTIC STREAMFLOW TIME SERIES
}

David Labat, B. Sivakumar, A. Mangin

\section{- To cite this version:}

David Labat, B. Sivakumar, A. Mangin. EVIDENCE FOR DETERMINISTIC CHAOS IN LONGTERM HIGH-RESOLUTION KARSTIC STREAMFLOW TIME SERIES. Stochastic Environmental Research and Risk Assessment, 2016, 30 (8), pp.2189-2196. hal-03239245

\author{
HAL Id: hal-03239245 \\ https://hal.science/hal-03239245
}

Submitted on 27 May 2021

HAL is a multi-disciplinary open access archive for the deposit and dissemination of scientific research documents, whether they are published or not. The documents may come from teaching and research institutions in France or abroad, or from public or private research centers.
L'archive ouverte pluridisciplinaire HAL, est destinée au dépôt et à la diffusion de documents scientifiques de niveau recherche, publiés ou non, émanant des établissements d'enseignement et de recherche français ou étrangers, des laboratoires publics ou privés. 
1 EVIDENCE FOR DETERMINISTIC CHAOS IN LONG-TERM HIGH-RESOLUTION

2 KARSTIC STREAMFLOW TIME SERIES

3 Labat D. ${ }^{1}$, Sivakumar B. ${ }^{2,3}$, Mangin A. ${ }^{4}$

$4 \quad 1$ - Géosciences Environnement Toulouse

52 - School of Civil and Environmental Engineering, The University of New South

$6 \quad$ Wales, Sydney, Australia

73 - Department of Land, Air and Water Resources, University of California,

8 Davis, USA

94 - Station d'Ecologie Expérimentale de Moulis - CNRS

12 Corresponding author :

13 David LABAT

14 Géosciences Environnement Toulouse - GET

15 14, Avenue Edouard Belin 31400 TOULOUSE FRANCE

16 国 (+33) 5.61.33.26.12

17 Fax: (+33) 5.61.33.25.60

18 E-mail: labat@get.obs-mip.fr 


\section{0}

Abstract One of the major challenges in hydrology consists in the conception of models to predict runoff evolution in time, as this is of crucial importance in water resource assessment and management. These models are required to provide estimations of high flows and low flows, so that appropriate short-term (flood) emergency measures and long-term (drought) management activities can be undertaken. However, due to the inherent nonlinearity of climate inputs (e.g. rainfall) and the heterogeneous nature of watersheds, understanding and modeling the catchment hydrologic response is tremendously challenging. This is particularly the case for karstic watersheds that are generally highly nonlinear and also sensitive to initial conditions. Investigation of the dynamic nature of hydrologic response is an important first step towards developing reliable models for such watersheds. To this end, this study examines the dynamic nature of streamflow discharge from karstic watersheds, especially the short-term variations. A nonlinear dynamic method, the correlation dimension method, is employed to unique long, continuous, and high-resolution (30-min) streamflow data from two karstic watersheds in the Pyrénées Mountains (Ariège) of France: the Aliou spring and the Baget spring. The results reveal the presence of deterministic chaos in the streamflow dynamics of the two watersheds, with attractor dimension values below 3 . These results have great significance regarding the presence of deterministic chaos in karstic flows and in the issue of data size regarding chaos studies in hydrology.

Keywords : Karstic springs, streamflow, nonlinearity, chaos, time series analysis, correlation dimension 


\section{Introduction}

If we consider a watershed as a hydrological "system", then we may consider rainfall as the principal input to the system and streamflow discharge (or a hydrobiogeochemistry index, such as conductivity, temperature, or bacteria distribution) as a representative output from the system. Therefore, study of discharge time series should give us relevant information on the hydrological behavior of the watershed that integrates the rainfall inputs and the different pathways of water in the several compartments of the watershed. This approach, based on the study of an input-output temporal relationship, known as the systemic analysis (Mangin, 1984), appears as a valuable paradigm in hydrology and hydrogeology. For a long time, this input-output relationship had been considered as linear (Labat et al., 2000). However, due to the co-existence of saturated or diphasic conditions with surface free or under pressure flow conditions, the dynamics of water and, hence, the rainfall-runoff relationship is inherently complex and nonlinear. As a result, estimation and prediction of discharge is very difficult. The problem is further complicated due to our inability to provide a precise knowledge of the initial conditions as well as the spatial and temporal variability of the physical parameters that control the transfer of water. This insufficient information limits our understanding and predictive ability.

Among all the different types of hydrological watersheds, arguably the least predictable remain the watersheds with underground karstic water pathways. Karstic aquifers constitute a freshwater resource that emerges from complex carbonate geological systems characterized by a high degree of heterogeneity. On one hand, these watersheds are characterized by unexpected flash floods, such as those occurred over the cities of Nimes (in the year 1988) or Vaison La Romaine (in the year 1992) in France, that cause human losses 
and severe economic damages. On the other hand, they will certainly play a key role in the future, as water demands continue to grow and the quantity of freshwater available (per capita) continues to shrink. The exploitation of these aquifers is much more difficult than porous, fissured and even fractured aquifers. This is a direct consequence of the dissolution of the limestone. When water infiltrates in the upper zone of the aquifer, it becomes acid because of the contact with the microfauna and the roofs that produce the acid carbonic. Therefore, when water percolates in the fractured carbonate media, the dissolution process favored by the existence of fractures or fissures involves the development of a high permeability together with the presence of micro- and macro-porosity. Water penetrates in the system via boreholes or sinks and then flows into drains and conduits connected to large water reserves (Labat et al., 2000). But this rapid infiltration contrasts with delayed infiltration via epikarstic soil. Saturated or diphasic conditions, together with surface free or under pressure flow conditions, generally co-exist and the dynamics of water in a watershed remains nonlinear and complex. The concomitance of both flows leads to a nonlinear response reflecting the large diversity of pathways connecting the surface with springs that involves complex hydraulic connections in the saturated zone. Karstic watersheds are then essentially spatially heterogeneous groundwater systems characterized by an inherent temporal nonstationarity and nonlinearity of their hydrological response that should be naturally investigated by nonlinear techniques, especially those that address the sensitivity to initial conditions (chaos).

First described by Lorenz in the context of meteorological models (Lorenz, 1963) and then connected to the concepts of fractal geometry by Mandelbrot (e.g. Mandelbrot, 1983), the theory of chaos has been successfully applied in many areas of engineering and natural sciences during the last three decades. Basically, a chaotic system is defined as a nonlinear 
deterministic system in which small changes in the initial conditions could lead to severe divergence in its future behavior. This property is obvious, for example, in global climate system, where it is popularly known as the "butterfly effect". Therefore, it is quite difficult to distinguish a chaotic deterministic system from a purely random system, since both of them can produce irregular and apparently unpredictable temporal and/or spatial variability. The theory of chaos in hydrological sciences was introduced in the late 1980s (e.g. Hense, 1987; Rodriguez-Iturbe et al., 1989). Since then, applications of chaos theory in hydrological sciences have been significantly advanced, including some very recent studies (e.g. Jayawardena et al., 2010; Kyoung et al., 2011; Sivakumar and Singh, 2012; Tongal et al., 2013; Tongal and Berndtsson, 2014); see, for example, Sivakumar $(2000,2004,2009)$ for detailed reviews.

A few important points must be noted from the literature on chaos studies on streamflow (and other hydrological) processes.

1. Thus far, chaos applications to streamflow processes have been largely limited to classical surface hydrological watersheds. However, as mentioned earlier, streamflow discharge from karstic springs may exhibit very different dynamics from that in surface hydrological watersheds. Therefore, whether streamflow from karstic springs exhibit chaotic behavior is an important question to study. To our knowledge, the study by Lambrakis et al. (2000) has been the only study that has attempted such an analysis, and further exploration is certainly worthwhile.

2. Chaos studies on streamflow time series (e.g. Lambrakis et al. (2000)) have largely focused on daily or coarser- resolution dynamics; with a few rare exceptions (e.g. Stehlik, 1999). While understanding the dynamics of streamflow at daily and coarser 
resolutions is indeed useful for various water resources and environmental applications, study of streamflow at much finer resolutions (e.g. in the order of hours and minutes) also serves important purposes, especially in the context of flood forecasting and emergency measures.

3. In almost all the chaos studies on streamflow, the length of data considered is less than $10^{4}$, which amounts to roughly 25 years of consecutive daily data at best; for instance, Lambrakis et al. (2000) have used just over 8000 values of daily data (22 years). Although reliable identification of chaotic behavior of streamflow can be made even with a few hundreds or just over a thousand of data representing a system (e.g. Jayawardena and Lai, 1994; Sivakumar et al., 2002b; Sivakumar, 2005), it is obviously desirable to have a much longer time series to eliminate any misgivings about the analysis and results.

These observations provide the motivation for the present study. In this study, we investigate the dynamics of long-term high-resolution streamflow data from two karstic systems in the Pyrénées Mountains (Ariège) of France: the Aliou spring and the Baget spring. We use streamflow data observed at every 30-minute resolution over a period of about 20 years, which amount to a total of over 350,000 values. We believe that these long-term, high-resolution discharge data provide the hydrological community the best opportunity for a highly reliable analysis of nonlinear and chaotic dynamics in karstic systems, and streamflow dynamics in general.

\section{Method}

A popular approach for detection of chaotic patterns in time series is based on the estimation of the correlation dimension, introduced by Grassberger and Procaccia (1983). 
137 The correlation dimension method uses the correlation integral to distinguish between

138 chaotic and stochastic systems. Let us assume that the time series under investigation is

139 generated by a nonlinear dynamical system with m-degree of freedom. It is first necessary to

140 construct a series of state vectors $X^{m}(t)$ (e.g. Packard et al., 1980). With observations of only

141 the variable of interest available, one way to deal with this reconstruction is by using delay

142 coordinates in an m-dimensional phase space (Takens, 1981):

$143 \quad X^{m}(t)=[X(t), X(t+\tau), \ldots, X(t+(m-1) \tau]$

144 where $\mathrm{m}$ is called the embedding dimension and $\tau$ is an appropriate delay time. These

145 vectors describe the trajectory of the system in the phase space. If the system is characterized by a low-dimensional chaotic behavior, the trajectories of the system will converge towards the subset of the phase space called "attractor." When dealing with natural processes, which are inherently nonlinear, convergence with a cyclic trajectory cannot be observed. Rather, nonlinear natural dynamical systems tend to converge on attractors on which the motion is periodic and unpredictable over long time, called "strange attractors."

The choice of the delay time is a very important step in phase space reconstruction and, hence, in the correlation integral estimation. It is well known that if the delay time is too small, the phase-space coordinates will not be independent enough to produce new information about the evolution of the system, whereas if it is too large then all the relevant information is lost because of diverging trajectories. Additionally, if the delay time is smaller than necessary to unfold the attractor, then the estimated correlation dimension from the 

where $v$ is the correlation exponent given by the slope of correlation integral versus radius in

a proper delay time: the autocorrelation function (Holzfuss and Mayer-Kress, 1986) and the mutual information function (Fraser and Swinney, 1986); see Islam and Sivakumar (2002) for an example of their applications for streamflow time series. In the autocorrelation function method, a common rule consists of setting the delay time as the lag time at which the autocorrelation function first reaches zero, but some authors have also suggested 0.1 (Tsonis and Elsner, 1988) or 0.5 (Schuster, 1988). In the mutual information method, the lag time corresponding to the first minimum of the mutual information is generally chosen as the delay time.

Considering the set of points in the attractor, one can define the correlation integral (or function) in order to distinguish between stochastic and chaotic behavior. In practice, when dealing with the sampled (not continuous) time series, the radius cannot tend to zero and the correlation integral is approximated numerically and computed as follows:

$$
C(r)=\frac{1}{N_{r e f}} \sum_{j=1}^{N_{\text {ref }}} \frac{1}{N} \sum_{i=1}^{N} \Theta\left(r-\left|X^{i}-X^{j}\right|\right)
$$

where $N$ is the number of points $X_{N}(t), N_{\text {ref }}$ is the number of reference points taken from $N$ and $\Theta(r)$ is the Heaviside function. Therefore, the correlation integral consists of an estimate of the number of points out of the data set which are closer than a radius $r$ or within an hypersphere of radius $r$. Then, when the radius tends towards zero, the correlation integral will be characterized by an asymptotic power-law behavior

$$
C(r) \propto r^{v}
$$
a log-log plot. In order to detect chaotic behavior, the correlation exponent has to be plotted 
against the embedding dimension $\mathrm{m}$. If the correlation exponent $v$ increases with the embedding dimension, then no chaotic behavior is present in the dynamical system. For example, a purely random process, where there is no determinism, is characterized by a linear increase of the correlation exponent with the embedding dimension without saturation value. If the correlation exponent $v$ reaches a saturation value, the asymptotic value is called the correlation dimension of the attractor. The correlation dimension is often fractal, meaning that it is a non-integer dimension typical from a chaotic system. The nearest integer above the correlation dimension is generally assumed to be the number of degrees of freedom of the system. This information is of great importance in the modeling and prediction process. The effective region of scaling in the $\log C(r)$ versus log $r$ plot is dictated principally by the possible presence of noise and so the intrinsic quality of the data (Lai and Lerner, 1998) and also by the proper determination of the delay time.

The correlation dimension method has been very widely used to distinguish between chaotic and stochastic time series in almost all fields. However, there have also been strong criticisms on the use of the method to real time series. Extensive details of the associated issues, including temporal correlations, data size, data noise, and presence of zeros, are already available in the literature (e.g. Osborne and Provenzale, 1989; Nerenberg and Essex, 1990; Theiler, 1990; Tsonis et al., 1993; Schreiber and Kantz, 1996; Sivakumar, 2005). The issue of data size, however, has often dominated criticisms on chaos studies in hydrology, since hydrologic time series are often very short; see, for example, Schertzer et al. (2002) and Sivakumar et al. (2002a) for a discussion. It is our hope that analysis of a very long time series will help to have more confidence in the search for the presence of chaos in hydrological time series. 
We focus here our attention on the analysis of long-term high-resolution streamflow records from karstic systems in order to highlight possible chaotic dynamics in their temporal variations. We study 30 -min discharge data observed over a period of about 20 years from two karstic springs of the Pyrénées Mountains (Ariège): the Aliou and the Baget springs (Figure 1). Owing to the geographic proximity of these mid-altitude basins, both basins are under the influence of the same rainfall input function. Both watersheds are characterized by similar hydrological indexes with a mean daily discharge around $0.5 \mathrm{~m}^{3} / \mathrm{s}$, an area around $13 \mathrm{~km}^{2}$ and a median altitude around 900m a.s.l.

The Aliou watershed, which is known as extremely karstified with a very short time response (less than a day), exhibits a discharge increase from $0.1 \mathrm{~m}^{3} / \mathrm{s}$ to nearly $30 \mathrm{~m}^{3} / \mathrm{s}$ in as little as 8 hours followed by a decrease that is equally quick (Figure 1, top). The 30 -min sampling rate was adopted in the first time by analogy with other karstic springs. However, we recently put in evidence that for these two karstic springs, it is the best sampling rate in term of information. Then, in order to verify that it is the best sampling rate in terms of information content in hydrologic processes, we consider here 3-min sampling rate for one year as demonstrated in Labat et al. (2011). The spectral density of such a discharge series shows that below the 30 -min timescale, the power spectrum density is flat meaning that there is only noise in the signal. It also shows a power-law behavior of the spectral density up to a 1hour period. Therefore, the 30 -min sampling time that has been adopted since the beginning of the 1990s, appears as the best compromise in terms of hydrological information. The Baget spring also exhibits a very short response time in flow dynamics (Figure 1, bottom), although the discharge is not as high as that for the Aliou spring. Figure 1 displays a 
visualization of the 30-min sampling rate for Aliou and Baget springs discharge time series (left) and compares it to the daily mean classical value (right). One can see that the 30-min data allow a far better resolution of the flood event than the classic daily mean sampling rate. It reveals the complete dynamics of the hydrological system response, especially the sharp rising part of flow (i.e. flood) within a short period for the two watersheds.

For analysis, we consider two different periods of data for each watershed: 1995-2000 and 2005-2015. Data from the intervening period 2000-2005 are not considered in this study, because continuous runoff measurements at high sampling rates could not be made due to several technical issues that were encountered during the measurement. With this, the longest series corresponds to more than 160,000 consecutive streamflow data. To our knowledge, this dataset constitutes the longest available series at this sampling rate on karstic system worlwide. The analysis of the power spectrum densities for the two longest discharge time series (Figure 2) highlight a power law behavior with a break-in-scale around 10 hours for Aliou and 16 hours for Baget. This break-in-scale, indicated in Figure 2 by a vertical line, corresponds to the frequency where the two power law behaviors cross. This is an indication that two stochastic processes can be deciphered in the discharge time series, corresponding to high-frequency and low-frequency processes. While the high-frequency process corresponds roughly to the response of the system to rainfall impulses, the lowfrequency process corresponds roughly to the response of the system to the synoptic climate variations.

We apply the correlation dimension method to identify the presence of chaotic dynamics in these two streamflow time series. The delay time is estimated based on the mutual information function, as it is a much better representation of nonlinear dynamics when 
compared to the autocorrelation function, which is essentially a linear tool. Nevertheless, for

251

252

the two time series considered here, the autocorrelation function method also offers somewhat similar values of delay time obtained using the mutual information. The estimated delay time value using the mutual information function method is 40 hours for the Aliou watershed and 60 hours for the Baget watershed (Figure 3), which is about 1.5 and 2.5 days, respectively. Both values are in good accordance with previous studies based on daily data on these watersheds over the 1970-2000 time period (Labat et al., 2000). By comparison, for example, a delay time of 7 days was selected in the study by Islam and Sivakumar (2002), 10 days by Elshorbagy et al. (2002), 14 days in Ng et al. (2007), and up to 146 days in Pasternack (1999).

Based on these delay time values, the data are reconstructed and the correlation integrals are estimated. Figure 4 shows, for five selected embedding dimensions, the correlation integral plots for the longer time series from Aliou and Baget. The correlation integral exhibits a power law behavior in the log-log plot, characterized by a linear behavior across low values of radius. Some authors have used the Takens-Theiler estimates of correlation dimension to identify the scaling regions more clearly (e.g. Wang et al., 2006), but here we prefer to identify the region where correlation between linear scaling and correlation integral presents the highest values.

The linear scaling regimes in these plots allow reliable determination of the slope, i.e. correlation exponent $(v)$. Figure $5(a)$ to $(d)$ show the relationship between the correlation exponent and embedding dimension for the four time series. For all the four time series, the correlation exponent $v$ first increases with the embedding dimension and then reaches a saturation value. The saturation value of the correlation exponent is 1.17 and 1.95 for the 
274

low and fractal values of the correlation exponents suggest the presence of low-dimensional deterministic dynamic nature of the four streamflow time series characterized by a certain number of dominant variables. The correlation exponent values also indicate that there are at least 2 or 3 independent variables dominantly governing the temporal dynamics of streamflow in the Aliou and Baget watersheds. More precisely, if we use $m>d$ (Takens, 1981) and $m \geq 2 d+1$ (Abarbanel et al., 1990) for the lower and upper limits of number of dominant variables, it can be concluded that different number of dominant variables are acting in streamflow dynamics for the different periods for the same basins. Both basins are located in the same zone and continuous and multiresolution wavelet analyses (not provided here) do not show any significant changes in the rainfall regimes during the two intervals. One may suspect, therefore, that the changes in the number of dominant variables can be related to the influence of snow on some winters or to some changes in the internal structure of karst in relationship with floods. For example, some hydraulic connections could have been changed due to the large amount of sediments and materials carried out by water in the drainage network.

The correlation dimension results for the Aliou and Baget watersheds provide further support to the results reported by most of the chaos studies in hydrology, at least from two perspectives:

(1) The dynamics of streamflow (and other hydrological processes), including in karstic watersheds, often exhibit low-dimensional chaotic behavior. This is particularly the case for high-resolution time series, such as those finer than daily, where the smoothing effects (which are often observed at daily scale due to averaging, as 
shown in Figure 1) are not significant; see also Regonda et al. (2004) and Salas et al.

297

298

299

300

301

302

303

304

305

306

307

308

309

310

311

312

313 (2005).

(2) Data size (in terms of the sheer number of values in time series) is not necessarily a serious limiting factor in the estimation of correlation dimension (or any other chaos indicator), as long as the time series is long enough to represent the essential features of the system dynamics; see also Sivakumar et al. (2002a, b) and Sivakumar (2005).

\section{Conclusion}

Considering the heterogeneous karstic systems, chaotic approach appears as a valuable method for determining the level of complexity of such systems. The chaos analysis gives relevant and useful information on the system not only for designing or exploitation of the water resources but also for flood prevention. Since previous studies on chaos applications in streamflow series have focused in a large majority on mean daily data, they could not account for the short-term variations in the streamflow process. Therefore, past results regarding the presence of chaotic behavior in streamflow may not be as strong as they can be. This study provides the first observation of chaotic behavior in long, continuous, and high-resolution (30-min) streamflow series from karstic systems.

It is important to note that streamflow process in karstic systems (and any hydrologic system for that matter) exhibits at least two different kinds of responses at different scales. The short-term response of the karstic systems (almost at daily scale) corresponds to the hydrologic response to a given rainfall event and highlights a large amount of the 
nonlinearity of the rainfall-runoff relationship. On the other hand, the medium- to long-term

response of the karstic system corresponds to its response to seasonality of rainfall. Considering these two different kinds of system responses and developing models to integrate them will likely offer a better way to study the streamflow dynamics. We strongly encourage hydrologists to apply nonlinear dynamic and chaos methods towards development of such an integrated framework in order to provide a new vision of the hydrological systems.

\section{Acknowledgments}

The database benefits from CRITEX Program RBV-SOERE from INSU-CNRS and Aliou and Baget watersheds are part of the French national observatory SO KARST (www.sokarst.org). B. Sivakumar acknowledges the financial support from the Australian Research Council (ARC) through the Future Fellowship grant (FT110100328).

\section{References}

- Abarbanel HDI, Brown R, Kadtke JB, 1990. Prediction in chaotic nonlinear systems: Methods for time series with broadband Fourier spectra. Physical Review A:1782-1807.

- Elshorbagy, A., Simonovic, S.P., Panu, U.S., 2002. Estimation of missing streamflow data using principles of chaos theory. Journal of Hydrology, 255(1-4): 123-133.

- Fraser, A.M., Swinney, H.L., 1986. Independent coordinates for strange attractors from mutual information. Phys. Rev. A 33(2), 1134-1140.

- Grasberger P. Proccacia I., 1983. Measuring the strangeness pf strange attractors, Physica D., 189.

- Hense, A., 1987. On the possible existence of a strange attractor for the southern oscillation. Beitr. Phys. Atmos., 60(1), 34-47.

- Holzfuss, J., Mayer-Kress, G., 1986. An approach to error-estimation in the application of dimension algorithms. In: Mayer-Kress, G. (Ed.). Dimensions and Entropies in Chaotic Systems, Springer, New York, pp. 114-122.

- Islam, M.N., Sivakumar, B., 2002. Characterization and prediction of runoff dynamics: a nonlinear dynamical view. Advances in Water Resources, 25(2): 179-190

- Jayawardena, A. W., Lai, F., 1994. Analysis and prediction of chaos in rainfall and stream flow time series. J. Hydrol., 153, 23-52. 
- Jayawardena, A.W., Xu, P.C., Li, W.K., 2010. Modified correlation entropy estimation for a noisy chaotic time series. Chaos, 20, 023104.

- Kyoung, M.S., Kim, H.S., Sivakumar, B., Singh, V.P., Ahn, K.S., 2011. Dynamic characteristics of monthly rainfall in the Korean peninsula under climate change. Stoch. Environ. Res. Risk. Assess., 25(4), 613-625.

- Labat, D., Ababou R., Mangin A., 2000. Rainfall-runoff relations for karstic springs. Part I: convolution and spectral analyses. Journal of Hydrology, 238(3-4), 123-148.

- Labat D., Masbou J., Beaulieu E., Mangin A., 2011. Scaling behavior of the fluctuations in stream flow at the outlet of karstic watersheds, France. Journal of Hydrology 410 (3), 162168.

- Lai Y.C., Lerner, D., 1998. Effective scaling regime for computing the correlation dimension from chaotic time series. Physica D, 115, 1-18.

- Lambrakis N., Andreou A.S., Polydoropoulos P., Georgopoulos E., Bountis T., 2000. Nonlinear analysis and forecasting of a brackish karstic spring. Water Resource Research, 36(4) 875884.

- Lorenz, E.N., 1963. Deterministic nonperiodic flow. Journal of the Atmospheric Sciences, 20, 130-141.

- Mandelbrot, B.B., 1983. The Fractal Geometry of Nature. Freeman, New York.

- Mangin A., 1984. Pour une meilleure connaissance des systèmes hydrologiques à partir des analyses corrélatoires et spectrales. Journal of Hydrology, 67, 25-43.

- Nerenberg, M.A.H., Essex, C., 1990. Correlation dimension and systematic geometric effects. Physical Review A, 42(12), 7065-7074.

- Ng, W.W., Panu, U.S., Lennox, W.C., 2007. Chaos based analytical techniques for daily extreme hydrological observations. Journal of Hydrology, 342: 17-41.

- Osborne, A.R., Provenzale, A., 1989. Finite correlation dimension for stochastic systems with power-law spectra. Physica D, 35, 357-381.

- Packard, N.H., Crutchfield, J.P., Farmer, J.D., Shaw, R.S., 1980. Geometry from a time series. Physical Review Letters, 45, 712-716.

- Pasternack, G.B., 1999. Does the river run wild? Assessing chaos in hydrological systems. Advances in Water Resources, 23(3): 253-260.

- Regonda S, Sivakumar B, Jain A (2004) Temporal scaling in river flow: can it be chaotic? Hydrol Sci J 49(3):373-385

- Rodriguez-Iturbe, I., De Power, F.B., Sharifi, M.B., Georgakakos, K.P., 1989. Chaos in rainfall. Water Resources Research, 25(7), 1667-1675.

- Salas JD, Kim HS, Eykholt R, Burlando P, Green TR (2005) Aggregation and sampling in deterministic chaos: implications for chaos identification in hydrological processes. Nonlinear Processes Geophysics 12:557-567

- Schertzer, D., Tchiguirinskaia, I., Lovejoy, S., Hubert, P., Bendjoudi, H., 2002. Which chaos in the rainfall-runoff process? A discussion on 'Evidence of chaos in the rainfall-runoff process' by Sivakumar et al. Hydrological Sciences Journal, 47(1), 139-147.

- Schreiber, T., Kantz, H., 1996. Observing and predicting chaotic signals: is $2 \%$ noise too much? In: Kravtsov, Yu.A., Kadtke, J.B. (Eds.). Predictability of Complex Dynamical Systems, Springer Series in Synergetics, Springer, Berlin, pp. 43-65.

- Schuster, H.G., 1988. Deterministic Chaos, VCH, Weinheim.

- Sivakumar B., 2000. Chaos theory in hydrology: important issues and interpretations. Journal of Hydrology 227 1-20.

- Sivakumar B., 2004. Chaos theory in geophysics: past, present and future. Chaos, Solitons and Fractals 19(2), 441-462.

- Sivakumar, B., 2005. Correlation dimension estimation of hydrologic series and data size requirement: myth and reality. Hydrological Sciences Journal, 50(4), 591-604. 
- Sivakumar, B., Singh, V.P., 2012. Hydrologic system complexity and nonlinear dynamic concepts for a catchment classification framework. Hydrol. Earth Syst. Sci., 16, 4119-4131.

- Sivakumar, B., 2009. Nonlinear dynamics and chaos in hydrologic systems: latest developments and a look forward. Stochastic Environmental Research and Risk Assessment, 23, 1027-1036.

- Sivakumar, B., Berndtsson, R., Olsson, J., Jinno, K., 2002a. Reply to 'which chaos in the rainfall-runoff process?' by Schertzer et al. Hydrological Sciences Journal, 47(1), 149-158.

- Sivakumar, B., Persson, M., Berndtsson, R., Uvo, C.B., 2002b. Is correlation dimension a reliable indicator of low-dimensional chaos in short hydrological time series? Water Resources Research, 38(2), doi: 10.1029/2001WR000333.

- Stehlik, J., 1999. Deterministic chaos in runoff series. Journal of Hydrology and Hydromechanics, 47(4), 271-287.

- Takens, F., 1981. Detecting strange attractors in turbulence: In: Rand, D.A., Young, L.S. (Eds.). Dynamical Systems and Turbulence, Lecture Notes in Mathematics, 898, Springer, Berlin, pp. 366-381.

- Theiler, J., 1990. Estimating the fractal dimension. Journal of Optical Society of America A, 7, 1055-1073.

- Tongal, H., Berndtsson, R., 2014. Phase-space reconstruction and self-exciting threshold modeling approach to forecast lake water levels. Stoch. Environ. Res. Risk Assess., 28(4), 955971.

- Tongal, H., Demirel, M.C., Booij, M.J., 2013. Seasonality of low flows and dominant processes in the Rhine River. Stoch. Environ. Res. Risk Assess., 27, 489-503.

- Tsonis, A.A., Elsner, J.B., 1988. The weather attractor over very short timescales. Nature, 333, 545-547.

- Tsonis, A.A., Elsner, J.B., Georgakakos, K.P., 1993. Estimating the dimension of weather and climate attractors: important issues about the procedure and interpretation. Journal of the Atmospheric Sciences, 50, 2549-2555.

Wang, W., Vrijling, J.K., Van Gelder, P.H.A.J.M., Mac, J., 2006. Testing for nonlinearity of streamflow processes at different timescales. Journal of Hydrology (322): 247-268. 
Figure 1: Visualization of the 30-min discharge time series for Aliou and Baget watersheds. Figure 1-a represents the two 30-min discharge times series for Aliou watershed and Figure 1-b compares 30min high resolution sampling rate and daily sampling rate for the flood corresponding to the restricted interval 2/12/1995-7/12/1995. Figure 1-c represents the two 30-min discharge time series for Baget watershed and Figure 1-d compares 30-min high resolution sampling rate and daily sampling rate for the flood corresponding to the restricted interval 9/6/2000-14/6/2000.

Figure 2: Power spectrum density function of the normalized frequency (in hours ${ }^{-1}$ ) for the longest discharge time series available for the Aliou (a) and Baget (b) karstic systems. The vertical line corresponds to the frequency where the two power law behaviors cross. It indicates that two stochastic processes can be deciphered in the discharge time series, corresponding to high-frequency and low-frequency process processes. The high-frequency process corresponds roughly to the response of the system to rainfall impulses, whereas the low-frequency process corresponds roughly to the response of the system to the synoptic climate variations

Figure 3: Average mutual information function of the time delay obtained for the longest discharge time series available on Aliou (a) and Baget (b) karstic systems. The first minimum roughly corresponds to 40 hours for Aliou watershed and 60 hours for Baget watershed.

Figure 4: Log-log plot of the correlation integral function for five selected embedding dimensions $\mathrm{m}$ obtained for the longest 30-min discharge time series on the Aliou (a) and Baget (b) watershed. The $C(r)$ function exhibits a clear power law behavior highlighted by the straight line.

Figure 5: Correlation exponent versus embedding dimension for discharge time series from Aliou and Baget watersheds. The top plots correspond, respectively, to the first (a) and second discharge time (b) series of Aliou watershed and the bottom plots correspond, respectively, to the first (c) and second (d) discharge time series of Baget watershed. The correlation exponent $v$ first increases with the embedding dimension and then reaches a saturation value. The saturation value $v$ of the correlation exponent is 1.17 and 1.95 for the Aliou streamflow time series and 2.75 and 1.55 for the Baget streamflow time series. 